\title{
Bıldırcın Rasyonlarına Farklı Oranlarda Sumak (Rhus Coriaria L.) illavesinin Besi Performansı, Oksidatif Stres Parametreleri ve Et Kalitesi Üzerine Etkisi
}

\author{
Nurcan KIRAR ${ }^{1, a,{ }^{*}}$ Osman BiLAL ${ }^{1, b}$ Aydın DAŞ ${ }^{2, c}$ ismail KOYUNCU ${ }^{3, d}$ Mehmet AVCI $^{4, e}$ Faruk BOZKAYA $^{5, f}$ \\ Gülçün BAYTUR ${ }^{1, g}$ Tuncay TUFAN ${ }^{6, h}$
}

\author{
${ }^{1}$ Harran Üniversitesi Sağlık Bilimler Enstitüsü, Şanlıurfa, Türkiye. \\ ${ }^{2}$ Harran Üniversitesi, Veteriner Fakültesi, Zootekni Anabilim Dalı, Şanlıurfa, Türkiye. \\ ${ }^{3}$ Harran Üniversitesi Tıp Fakültesi Temel Tıp Bilimleri Bölümü Tıbbi Biyokimya Anabilim Dalı, Şanlıurfa, Türkiye. \\ ${ }^{4}$ Harran Üniversitesi, Veteriner Fakültesi, Hayvan Besleme ve Beslenme Hastalıkları Anabilim Dalı, Şanlıurfa, Türkiye. \\ ${ }^{5}$ Harran Üniversitesi Veteriner Fakültesi Genetik Anabilim Dalı. Şanlıurfa, Türkiye. \\ ${ }^{6}$ Siirt Üniversitesi Veteriner Fakültesi Zootekni ve Hayvan Besleme Bölümü Anabilim Dalı, Siirt, Türkiye. \\ aORCID: 0000-0002-2778-1789, bORCID:0000-0002-4404-6516, 'ORCID: 0000-0003-0371-5434, dORCID: 0000-0002-9469- \\ 4757, eORCID: 0000-0002-2523-2137, fORCID: 0000-0001-6423-8067, gORCID: 0000-0002-1878-3862, \\ hORCID: 0000-0001-8420-4235
}

Özet: Bu çalışma; Japon bıldırcınlarının yemlerine farklı seviyelerde ilave edilen sumağın canlı ağırlık kazancı (CAK), yem tüketimi (YT), yemden yararlanma oranı (YYO), oksidatif stres parametreleri ve et kalitesi üzerine etkilerini belirlemek amacıyla yapılmıştır. Çalışmada 10 günlük yaşta 120 adet karışık cinsiyette Japon bıldırcın biri kontrol grubu olmak üzere rastgele 4 gruba ayrılmıştır. Her gruptaki hayvanlar ikişerli olarak 15 tekerrüre ayrılmıştır. Bıldırcın yemlerine sırayla \%0, \%1, $\% 2$ ve \%3 sumak tozu ilave edilmiş olup rasyonlar izokalorik ve izonitrojenik olarak hazırlanmıştır. Çalışmada sumak ilavesinin CAK, YT ve YYO' na etkisinin olmadığı belirlenmiştir. Sumak ilavesi CAK, YT ve YYO' nı etkilemezken, gruplar arasında sırt ve but ağırlıkları açısından önemli farklılıklar gözlemlenmiştir $(P<0.05)$. En düşük sırt ağırlığının $27,12 \mathrm{~g}$ ile $\% 3$ sumak grubunda, en yüksek ağırlığın ise $32,70 \mathrm{~g}$ ile kontrol grubunda olduğu belirlenmiştir. En düşük but ağırlığı 26,22 g ile $\% 3$ sumak grubunda ve en yüksek 29,14 g ile kontrol grubunda tespit edilmiştir $(P<0,05)$. Ayrıca çalışmada sumağın 1 . ve 24 . saatlerde göğüs eti $\mathrm{pH}^{\prime}$ sı ile göğüs eti L*, a* ve b* değerleri bakımından gruplar arasında fark oluşturmadığı belirlenmiştir. Kanda toplam antioksidan durum (TAS) değeri en yüksek \%3 sumakta en düşük ise kontrol grubunda görülmüştür $(P<0,05)$. Oksidatif stres indeksi (OSi) değeri en yüksek kontrol grubunda en düşük ise \%3 sumak grubunda olduğu tespit edilmiştir $(\mathrm{P}<0.05)$. Sonuç olarak bıldırcın rasyonlarına sumak ilavesinin besi performansı, karkas özellikleri ve et kalitesini değiştirmediği ancak kandaki TAS değerlerini yükselttiği ve OSi değerlerini düşürdüğü için rasyona sumak ilavesinin faydalı olacağı görülmüştür.

Anahtar Kelimeler: Japon bıldırcını, Performans, Sumak, Oksidatif stres indeksi, Toplam antioksidan durum, Toplam oksidatif durum.

\section{Effects of Dietary Addition of Different Rates Sumac (Rhus Coriaria L.) Powder on Growth Performance, Meat Quality, Carcass Composition and Oxidative Stress Markers of Japanese Quail}

Abstract: This study was conducted to determine the effects of sumac (Rhus Coriaria L.) on body weight gain (BWG), feed consumption (FC), feed conversion rate (FCR), oxidative stress parameters, and meat quality added to the feed of Japanese quails. In the study, 120 10-day-old mixed-sex Japanese quail were randomly divided into 4 groups of 15 birds each. Into the feed of the quails $1 \%, 2 \%$, and $3 \%$ sumac powder were added. The control group was given a diet without sumac. The diets were prepared as isocaloric and isonitrogenic. In the study, it was determined that the addition of sumac had no effect on BWG, FC, FCR, while significant differences were observed among groups with respect to back and thigh weights $(P<0.05)$. It was determined that the lowest back weight was in the $3 \%$ sumac group with $27.12 \mathrm{~g}$ while the highest was in the control group with $32.70 \mathrm{~g}$. The lowest thigh weight was in the $3 \%$ sumac group with $26.22 \mathrm{~g}$ and the highest in the control group with $29.14 \mathrm{~g}(\mathrm{P}<0,05)$. In addition, it was determined that sumac did not cause any difference between the groups in terms of breast meat $\mathrm{pH}$ and breast meat $\mathrm{L} *, \mathrm{a} *$ and $\mathrm{b} *$ values at first and 24th hours. Total antioxidant status (TAS) value in blood was highest in $3 \%$ the sumac and lowest in the control group $(P<0.05)$. The oxidative stress index (OSI) was the highest in the control group and the lowest in the $3 \%$ sumac group $(P<0.05)$. As a result, it has been observed that the addition of sumac to quail rations did not change the fattening performance, carcass characteristics, and meat quality, but increased the TAS values in the blood and decreased the OSI values.

Keywords: Japanese quail, Oxidative stress index, Performance, Rhus Coriaria L, Total antioxidant status, Total oxidative status. 


\section{Giriş}

Ülkemiz hayvancılığının gelişmesi için hayvanların besin madde gereksinimlerini yeterli ve dengeli bir şekilde karşılayacak rasyonlarla beslenmeleri gerekmektedir. Kanatlı üretiminde ve ürünlerinde yaşanan kayda değer artış, genetik ilerleme yanında besleme, yem ve yem teknolojisindeki gelişmeler ile yakından ilişkili olup disiplinler arası yoğun çalışmalarının ortak sonucudur (Kutlu ve Şahin, 2017).

Bıldırcınlar düşük kolesterollü et üretimi, yüksek yumurta verimi ve büyüme hızı, erken cinsel olgunluğa erişme ve düşük yetiştirme masraflarıyla son yıllarda dikkatleri üzerinde toplayan bir kümes hayvanıdır. Ülkemizde bıldırcın yumurtası ve etine olan talebin artması bıldırcın üretiminin gelişmesini ve günden güne büyüyen bir sektör haline gelmesini sağlamıştır. Ancak diğer kanatlı hayvanlarda olduğu gibi bıldırcınlarda da toplam giderlerin yaklaşık \%7580'ni yem giderleri oluşturmaktadır. Bu nedenle araştırıcılar tüm giderler içerisinde en büyük payı oluşturan yem giderlerini azaltabilmek için alternatif yem kaynakları ya da yem katkı maddeleri bulmayı amaçlamışlardır (Çimrin, 2012).

Sumak (Rhus coriaria L.) Anacardiaceous familyasına ait Asya ülkelerinde yaygın olarak yetişen bir bitkidir (Shidfar ve ark., 2014). Geleneksel olarak sumak ilaç endüstrisinde kullanılmaktadır. Gastrit mide kanseri ve aterosklerozis tedavisinde kullanılan sumağın ana bileşikleri tanenlerdir. Bununla birlikte sumak, B vitaminleri ve ayrıca gallik asit bakımından da zengindir. Sumak tohumları çok iyi bir gallotannis, uçucu yağ ve antosiyanin kaynağıdır (Ghasemi ve ark., 2014). Sumak potasyum, kalsiyum, magnezyum ve fosfor gibi birçok mineral bakımından zengindir (Gümüş ve ark., 2018). Bazı araştırmacılar, diyete sumak ilavesinin bıldırcınlarda büyüme performansını iyileştirdiğini bildirmiştir (Zavaragh, 2011).

$\mathrm{Bu}$ çalışmanın amacı, Japon bıldırcınlarının (Coturnix Coturnix Japonica) diyetine farklı oranlarda sumak ilavesinin besi performansı, oksidatif stres parametreleri ve et kalitesi üzerine etkisini araştırmaktır.

\section{Materyal ve Metot}

Denemede 10 günlük yaşta toplam 120 adet Japon bıldırcını (dişi ve erkek) kullanılmıştır. Deneme, 5 katlı her katında birbirinden bağımsız raydan ve ışıklandırma amacıyla ampul bulunan ana makinalarında yürütülmüştür. İlk 10 gün yem ve su özel kaplarla bölme içindeki ızgara üzerinde verilmiş ve daha sonra ana makinasında mevcut yemlik ve suluklar kullanılmıştır. Toplam 120 bıldırcın, her bir grupta 15 tekerrürden her tekerrürde de 2 hayvan bulunacak şekilde tesadüfi parseller deneme desenine göre 60 kafes bölmesine rastgele dağıtılmıştır. Böylece araştırma 1 kontrol ve 3 deneme grubu olmak üzere toplam 4 grup halinde yürütülmüştür. Deneme gruplarının karma yemleri kontrol grubu \%0 (I. Grup), \%1 (II. Grup) \%2 (III. Grup) ve \%3 (IV. Grup) sumak ilave edilerek izokalorik ve izonitrojenik olarak hazırlanmıştır ve araştırma 4 hafta sürdürülmüştür. Deneme grubu yemleri hazırlanırken yeme katılacak sumak önce kendi miktarlarının on katı kadar yemle iyice karıştırılmış, daha sonra geniş bir kova içerisinde üzerine azar azar yem ilave edilerek homojen bir karışım elde edilmiştir.

Araştırmada kullanılan yem maddeleri ve karma yemlerin ham besin madde içerikleri NRC (1994)'ye göre yapılmıştır. Denemede kullanılan karma yemlerin hammadde bileşimi ve besin madde içerikleri Tablo 1'de verilmiştir. Çalışmada katkı maddesi olarak kullanılan sumağın besin madde içeriği KM \%98, HP \%3, HY \%12, HK \%2.8, ME 2000 $\mathrm{kcal} / \mathrm{kg}$ olarak belirlenmiştir.

Araştırmada, hayvanların canlı ağılıkları (CA) ve canlı ağırlık kazançları (CAK) 4 hafta süresince haftada bir kez olmak üzere $0.01 \mathrm{~g}$ hassasiyette elektronik terazi ile tartılarak belirlenmiştir. Ayrıca yemler haftalık olarak tartılmış yem tüketimi (YT) ve yemden yararlanma oranı (YYO) hesaplanmıştır.

Çalışma sonunda kesim ve karkas parametrelerinin belirlenmesi için her grupta 10 adet olmak üzere toplam 40 bıldırcın kesilmiştir. Bıldırcınlarının göğüs eti örneklenerek $\mathrm{pH}$ ve renk ölçümleri için değerlendirilmiştir. Karaciğer, kalp, taşlık ve dalak ağırlıkları aynı terazi ile tartılarak belirlendi. İç organlar çıkarıldıktan sonra karkas tartılarak sıcak karkas ağırlığı belirlenmiştir. Daha sonra sonra Genchev ve Mihaylov (2008)'a göre karkaslar parçalandı. Karkasta gögüs, sırt+boyun, but ve kanat ağırıkları belirlendi.

Çalışma sonunda her gruptan kesilen hayvanların göğüs etinde (derisiz) parlaklık $\left(L^{*}\right)$, kırmızı renk $\left(a^{*}\right)$, sarı renk $\left(b^{*}\right)$ ölçümleri 3 ayrı noktadan 1. ve 24. saatte belirlendi. Et renginin ölçümünde Lovibond (RT SERIES for MODEL SP60) cihaz kullanıldı. pH ölçümleri Testo 205 cihazı kullanılarak 1. ve 24 . saatte yapıldı.

Oksidatif stres ve antioksidanların durumunu belirlemek üzere kesim sırasında her grupta 10 hayvandan ETDA'lı tüplere alınan kanlar 3000 rpm'de $10 \mathrm{dk}$ santrifüj edildikten sonra plazmaları alındı ve $-80^{\circ} \mathrm{C}^{\prime}$ de analiz edilinceye kadar bekletildi. Toplam oksidatif stres (TOS) ve toplam antioksidan kapasite (TAS) ticari kit (Rel assay, Türkiye) 
Tablo 1. Denemede kullanılan karma yemlerin bileşimi ve besin madde değerleri (\%) ile metabolize olabilir enerji içerikleri (Kcal/kg).

\begin{tabular}{|c|c|c|c|c|}
\hline Ham madde & Kontrol & Sumak \%1 & Sumak $\% 2$ & Sumak \%3 \\
\hline Buğday & 17.49 & 13.80 & 13.50 & 10.61 \\
\hline Misır & 43.45 & 45.44 & 44.74 & 46.00 \\
\hline Balık unu & 0.20 & 0.20 & 0.20 & 0.20 \\
\hline Soya fasulyesi küspesi (44 \% CP) & 35.30 & 36 & 36 & 36.62 \\
\hline Bitkisel yağ & 0.50 & 0.50 & 0.50 & 0.50 \\
\hline Sumak & - & 1.00 & 2.00 & 3.00 \\
\hline Mermer tozu & 0.97 & 0.97 & 0.97 & 0.96 \\
\hline Dikalsiyum fosfat & 1.26 & 1.26 & 1.26 & 1.28 \\
\hline DL.Metiyonin & 0.10 & 0.10 & 0.10 & 0.10 \\
\hline L-Lizin & 0.06 & 0.06 & 0.06 & 0.06 \\
\hline Sodyum bikarbonat & 0.12 & 0.12 & 0.12 & 0.12 \\
\hline Tuz & 0.25 & 0.25 & 0.25 & 0.25 \\
\hline Vitamin-Mineral & 0.30 & 0.30 & 0.30 & 0.30 \\
\hline Toplam & 100 & 100 & 100 & 100 \\
\hline \multicolumn{5}{|l|}{ Analiz Değerleri (\%) } \\
\hline Kuru madde & 86.3 & 86.2 & 86.3 & 86.2 \\
\hline Ham protein & 24.0 & 24.0 & 24.0 & 24.0 \\
\hline Ham yağ & 2.69 & 2.76 & 2.84 & 2.91 \\
\hline Ham selüloz & 2.68 & 2.78 & 2.89 & 2.99 \\
\hline Ham kül & 5.73 & 5.76 & 5.77 & 5.82 \\
\hline \multicolumn{5}{|l|}{ Hesaplanmış Değer (\%) } \\
\hline ME & 2903 & 2906 & 2898 & 2897 \\
\hline $\mathrm{Ca}$ & 0.80 & 0.80 & 0.80 & 0.80 \\
\hline Kullanılabilir fosfor & 0.30 & 0.30 & 0.30 & 0.30 \\
\hline Met+Sistin & 0.86 & 0.85 & 0.85 & 0.85 \\
\hline Lizin & 1.31 & 1.33 & 1.32 & 1.33 \\
\hline
\end{tabular}

Bir kg karma yemdeki vitamin-mineral değerleri ; A vitamini 12.000. IU; D3 vitamini 5.000. IU; E vitamini 50 mg; K3 vitamini 4. mg; B1 vitamini 3 mg; B2 vitamini 6 mg; Niasin 40 mg; Kalsiyum D-pantotenat 15mg; B6 vitamini 5 mg; B12 vitamini 0.03 mg; Folik Asit 1 mg; Biotin 0.075 mg; Kolin Klorid 400 mg. C vitamini 50 mg ve antioksidan 10 mg . Manganez 120 mg Demir 40mg; Çinko 110 mg; Bakır 16 mg; Kobalt 0.005 mg; lyot 0.125 mg; Selenyum $0.003 \mathrm{mg}$.

protokolüne göre yapıldıktan sonra oksidatif stres indeksi (OSI) kitte belirtilen protokole göre hesaplandı. Protein oksidasyonu (AOPP) Başkol ve ark., (2014)'nın belirttiği Witko yöntemi ile, total thiol seviyesi ise 2,2-ditiobis nitrobenzoik (DTNB) yöntemi ile spektrofotometrik olarak tespit edildi.

Elde edilen sonuçlar SPSS (1999) paket programında tek yönlü varyans analizi ile değerlendirilmiştir. Gruplar arası farkın önemi Duncan testine göre değerlendirilmiştir.

\section{Bulgular}

Bıldırcın rasyonlarına farklı oranlarda sumak ilavesinin canlı ağırlıkları üzerine etkileri Tablo 2'de verilmiştir. Canlı ağırlık ortalamaları açısından tüm gruplar arasında fark bulunmamıştır $(P>0,05)$.

Sumak ilavesinin bıldırcınların performansı üzerine etkisi Tablo 3'te de görüldüğü üzere haftalık canlı ağırlık kazancı (CAK), yem tüketimi (YT) ve yemden yararlanma oranı (YYO) açısından gruplar arasında istatistiki olarak fark bulunmamıştır $(P>0,05)$.

Araştırmada sumağın kesim özellikleri ve iç organ ağırlıkları üzerine etkisinin verildiği Tablo 4 . incelendiğinde sırt ve but ağırlıkları dışında incelenen kesim ve karkas ağırlıkları açısından gruplar arasında fark bulunmamıştır. Sırt ağırığı en düşük \%3 sumak grubunda, en yüksek ise kontrol grubunda olduğu tespit edilmiştir $(P=0.026)$. Ayrıca but ağırlığı da en düşük \%3 sumak grubunda en yüksek ise kontrol grubunda olduğu belirlenmiştir $(\mathrm{P}=0.049)$.

Japon bıldırcınlarında sumağın göğüs et kalitesi özelliklerinden olan $\mathrm{pH}$ ve göğüs eti renk özellikleri $\left(L^{*}, a^{*}\right.$ ve $\left.b^{*}\right)$ üzerine 1 . ve 24 . saatlerdeki etkisi, tablo 5 verilmiştir. Tablo irdelendiğinde gruplar arasında istatistiki olarak fark bulunmamıştır $(P>0,05)$.

Japon bıldırcınlarında sumak ilavesinin oksidatif stres ve antioksidan kapasiteleri bakımından gruplar arasında farklılıklar önemli bulunmuştur (Tablo 6). TAS değeri en yüksek \%3 sumakta en düşük ise kontrol grubunda görülmüştür ( $P=0.000)$. OSi değeri en yüksek kontrol grubunda en düşük ise \%3 sumak grubunda olduğu tespit edilmiştir $(P=0,000)$.

\section{Tartışma ve Sonuç}

Avrupa Birliği tarafından, antibiyotiklerin yem katkı maddesi olarak kullanımının yasaklanması, araştırıcıları antibiyotiklere alternatif yem katkı maddeleri bulmaya yönlendirmiştir. Kanatlı hayvanların verim düzeylerini yükseltmek için doğal ve şifalı bitkilerin yem katkı maddesi olarak kullanılmasına ilgi artmaktadır.

Kanatlı hayvanlarının performansını, sağlığını ve ürünlerin kalitesini artırmak için yem katkı maddesi olarak bitkiler ve ekstraktları antibiyotiklere alternatifler olarak kullanılmıştır 
Tablo 2. Rasyona Sumak İlavesinin bıldırcınların canlı ağılık üzerine etkisi (g)

\begin{tabular}{|c|c|c|c|c|c|}
\hline Gruplar & $\begin{array}{c}\text { BCA } \\
\text { Ort } \pm S E\end{array}$ & $\begin{array}{c}\text { CA1. Hafta } \\
\text { Ort } \pm S E\end{array}$ & $\begin{array}{l}\text { CA2. Hafta } \\
\text { Ort } \pm S E\end{array}$ & 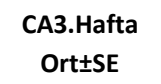 & $\begin{array}{l}\text { CA4. Hafta } \\
\text { Ort } \pm S E\end{array}$ \\
\hline Kontrol & $53.12 \pm 1.17$ & $95.11 \pm 2.04$ & $135.98 \pm 2.35$ & $171.88 \pm 3.86$ & $197.22 \pm 5.27$ \\
\hline Sumak \%1 & $53.41 \pm 1.28$ & $96.13 \pm 2.03$ & $136.22 \pm 2.21$ & $174.20 \pm 3.62$ & $198.48 \pm 4.97$ \\
\hline Sumak $\% 2$ & $52.8 \pm 1.31$ & $89.20 \pm 2.71$ & $128.32 \pm 3.09$ & $163.78 \pm 3.88$ & $187.35 \pm 4.32$ \\
\hline Sumak \%3 & $53.01 \pm 1.26$ & $90.78 \pm 2.30$ & $129.59 \pm 2.61$ & $169.11 \pm 3.52$ & $198.03 \pm 5.00$ \\
\hline $\mathrm{P}$ & 0.987 & 0.099 & 0.058 & 0.222 & 0.307 \\
\hline
\end{tabular}

BCA: Başlangıç canlı ağılık, CA1. Hafta:1.hafta canlı ağırlık, CA2. Hafta: 2.hafta canlı ağılık, CA3. Hafta: 3.hafta canlı ağırlık, CA4.Hafta: 4.hafta canlı ağırlık, Önemsiz: $P>0.05$

Tablo 3. Sumak ilavesinin bıldırcınların besi performansı üzerine etkisi

\begin{tabular}{|c|c|c|c|c|c|c|}
\hline & Gruplar & 1.hafta & 2.hafta & 3.hafta & 4.hafta & 1-4hafta \\
\hline & Gruplar & Ort $\pm S E$ & Ort $\pm S E$ & Ort $\pm S E$ & Ort $\pm S E$ & Ort $\pm S E$ \\
\hline CAK (g) & Kontrol & $41.9914 \pm 1.36$ & $40.8714 \pm 1.12$ & $38.0414 \pm 1.98$ & $25.3377 \pm 1.96$ & $144.4250 \pm 4.56$ \\
\hline \multirow[t]{3}{*}{ (Haftalık) } & Sumak\%1 & $42.7220 \pm 1.59$ & $40.0940 \pm .78$ & $37.9827 \pm 2.09$ & $24.2807 \pm 1.92$ & $145.0713 \pm 3.95$ \\
\hline & Sumak\%2 & $36.4147 \pm 2.40$ & $39.1280 \pm .88$ & $35.4573 \pm 1.79$ & $23.5753 \pm 1.31$ & $134.5687 \pm 2.89$ \\
\hline & Sumak\%3 & $37.8079 \pm 2.23$ & $38.8200 \pm 1.14$ & $39.5229 \pm 1.82$ & $28.9214 \pm 2.23$ & $145.0657 \pm 3.00$ \\
\hline $\mathrm{P}$ & & 0.067 & 0.461 & 0.515 & 0.197 & 0.120 \\
\hline $\mathrm{YT}(\mathrm{g})$ & Kontrol & $112.9429 \pm 3.83372$ & $149.0664 \pm 2.93603$ & $169.4093 \pm 7.09408$ & $195.4636 \pm 11.33132$ & $626.8764 \pm 20.12075$ \\
\hline \multirow[t]{3}{*}{ (Haftalık) } & Grup1 & $112.0280 \pm 3.27391$ & $148.0373 \pm 2.70206$ & $176.9787 \pm 8.26785$ & $179.0847 \pm 11.64231$ & $616.1227 \pm 18.36714$ \\
\hline & Grup 2 & $97.0873 \pm 5.82252$ & $140.4033 \pm 3.36923$ & $158.0793 \pm 8.47971$ & $187.3667 \pm 9.88777$ & $582.9293 \pm 14.69580$ \\
\hline & Grup3 & $103.6671 \pm 5.66875$ & $141.4914 \pm 3.11764$ & $182.6736 \pm 6.13829$ & $207.3971 \pm 11.49201$ & $635.2221 \pm 16.28982$ \\
\hline $\mathrm{P}$ & & 0.070 & 0.108 & 0.130 & 0.327 & 0.168 \\
\hline $\begin{array}{c}\mathrm{YYO}(\mathrm{g} Y \mathrm{YT} / \mathrm{g} \\
\text { CAK) }\end{array}$ & Kontrol & $2.6929 \pm 0.04290$ & $3.6621 \pm 0.05494$ & $4.4921 \pm 0.08697$ & $7.6583 \pm 0.20314$ & $4.3414 \pm 0.04124$ \\
\hline \multirow[t]{3}{*}{ (Haftalık) } & Grup 1 & $2.6387 \pm 0.04701$ & $3.6993 \pm 0.04893$ & $4.6980 \pm 0.08410$ & $7.5280 \pm 0.21466$ & $4.2480 \pm 0.06077$ \\
\hline & Grup 2 & $2.6913 \pm 0.05087$ & $3.5973 \pm 0.07766$ & $4.4947 \pm 0.14183$ & $7.9820 \pm 0.12095$ & $4.3327 \pm 0.05157$ \\
\hline & Grup 3 & $2.7600 \pm 0.03263$ & $3.6686 \pm 0.08491$ & $4.6764 \pm 0.12474$ & $7.3586 \pm 0.26063$ & $4.3793 \pm 0.06373$ \\
\hline $\mathrm{P}$ & & 0.299 & 0.747 & 0.401 & 0.172 & 0.392 \\
\hline
\end{tabular}

CAK: Canlı ağırlık kazancı, YT: Yem tüketimi, YYO: Yemden yararlanma oranı, Önemsiz (P > 0.05)

Tablo 4. Sumak ilavesinin bıldırcınların kesim ve iç organ ağılıkları üzerine etkisi (g).

\begin{tabular}{|c|c|c|c|c|c|}
\hline & $\begin{array}{l}\text { Kontrol } \\
\text { Ort } \pm S E\end{array}$ & $\begin{array}{l}\text { \%1Sumak } \\
\text { Ort_SE }\end{array}$ & $\begin{array}{l}\text { \%2Sumak } \\
\text { Ort } \pm \text { SE }\end{array}$ & $\begin{array}{l}\text { \%3Sumak } \\
\text { Ort } \pm \text { SE }\end{array}$ & $\mathbf{p}$ \\
\hline Karkas ağırlığı & $117,70 \pm 4,09$ & $118,50 \pm 4,52$ & $107,66 \pm 5,30$ & $104,66 \pm 2,43$ & 0.062 \\
\hline Göğüs & $45.14 \pm 2.37$ & $47.54 \pm 2.60$ & $43.32 \pm 2.17$ & $41.70 \pm 1.05$ & 0,231 \\
\hline Sirt+boyun & $32.70 \pm 1.18^{a}$ & $31.35 \pm 1.38^{\mathrm{ab}}$ & $28.23 \pm 1.58^{\mathrm{bc}}$ & $27.12 \pm 1.06^{c}$ & 0.026 \\
\hline But & $29.14 \pm 0.80^{a}$ & $29.09 \pm 0.7^{a}$ & $26.79 \pm 1.26^{a b}$ & $26.22 \pm 0.50^{b}$ & 0.049 \\
\hline Kanat & $9.02 \pm 0.32$ & $8.82 \pm 0.36$ & $8.24 \pm 0.42$ & $8.17 \pm 0.22$ & 0,259 \\
\hline Karaciğer & $4.96 \pm 0.74$ & $4.54 \pm 0.41$ & $4.03 \pm 0.52$ & $3.56 \pm 0.30$ & 0.239 \\
\hline Taşlık & $4.15 \pm 0.30$ & $4.37 \pm 0.23$ & $4.40 \pm 0.23$ & $3.98 \pm 0.26$ & 0.589 \\
\hline Kalp & $1.62 \pm 0.09^{b}$ & $1.91 \pm 0.11^{\mathrm{a}}$ & $1.72 \pm 0.08^{\mathrm{ab}}$ & $1.58 \pm 0.063^{b}$ & 0.050 \\
\hline Dalak & $0.12 \pm 0.02$ & $0.11 \pm 0.02$ & $0.13 \pm 0.02$ & $0.13 \pm 0.024$ & 0871 \\
\hline
\end{tabular}

a. b. c: aynı satırdaki farklı harflerle gösterilen ortalamalar arasındaki farklar önemlidir. $(P<0.05)$ 
Tablo 5. Sumak ilavesinin bıldırcınların göğüs eti renk özellikleri üzerine etkisi.

\begin{tabular}{|c|c|c|c|c|c|}
\hline Gruplar & Kontrol & \%1 Sumak & \%2 Sumak & \%3 Sumak & $p$ \\
\hline & Ort $\pm S E$ & Ort $\pm S E$ & Ort $\pm S E$ & Ort $\pm S E$ & \\
\hline $\mathrm{pH}_{1}$ & $6,11 \pm 0,04$ & $6,22 \pm 0,08$ & $6,16 \pm 0,02$ & $6,15 \pm 0,07$ & 0,723 \\
\hline $\mathrm{pH}_{24}$ & $5,91 \pm 0,05$ & $6,05 \pm 0,05$ & $5,91 \pm 0,03$ & $5,86 \pm 0,05$ & 0,841 \\
\hline $\mathrm{L}^{*}{ }_{1}$ & $44,54 \pm 1,72$ & $45,21 \pm 0,75$ & $45,69 \pm 0,71$ & $45,84 \pm 1,06$ & 0,057 \\
\hline$L^{*}{ }_{24}$ & $56,55 \pm 1,26$ & $55,03 \pm 0,93$ & $56,87 \pm 0,65$ & $57,44 \pm 1,03$ & 0,314 \\
\hline$a *_{1}$ & $9,60 \pm 0,71$ & $10,73 \pm 0,61$ & $9,98 \pm 0,50$ & $8,48 \pm 0,50$ & 0,051 \\
\hline$a *_{24}$ & $11,87 \pm 0,77$ & $12,57 \pm 0,47$ & $12,33 \pm 0,55$ & $10,36 \pm 0,75$ & 0,306 \\
\hline b* ${ }_{1}$ & $9,22 \pm 0,46$ & $10,29 \pm 0,45$ & $9,90 \pm 0,16$ & $9,62 \pm 0,46$ & 0,069 \\
\hline b* ${ }_{24}$ & $12,66 \pm 0,44$ & $13,41 \pm 0,44$ & $13,32 \pm 0,25$ & $13,66 \pm 0,52$ & 0,471 \\
\hline
\end{tabular}

L*: Parlaklık, a*: Kırmızı renk koordinatı, b*: Sarı renk koordinatı

Tablo 6. Sumak ilavesinin bıldırcınların oksidatif stres parametreleri üzerine etkisi.

\begin{tabular}{|c|c|c|c|c|c|}
\hline Gruplar & Kontrol & \%1 Sumak & \%2 Sumak & \%3 Sumak & $p$ \\
\hline & Ort $\pm S E$ & Ort \pm SE & Ort $\pm S E$ & Ort $\pm S E$ & \\
\hline TAS & $1,24 \pm 0,03^{c}$ & $1,41 \pm 0,05^{b}$ & $1,52 \pm 0,05^{b}$ & $1,70 \pm 0,06^{a}$ & 0.000 \\
\hline TOS & $15,02 \pm 0,82$ & $14,45 \pm 0,71$ & $13,48 \pm 0,45$ & $12,95 \pm 0,42$ & 0.089 \\
\hline osi & $1,20 \pm 0,04^{a}$ & $1,03 \pm 0,06^{b}$ & $0,89 \pm 0,05^{b c}$ & $0.76 \pm 0,02^{c}$ & 0.000 \\
\hline TOTAL THIOL & $0,22 \pm 0,02$ & $0,32 \pm 0,04$ & $0.26 \pm 0,06$ & $0.32 \pm 0,03$ & 0.414 \\
\hline AOPP & $0.63 \pm 0.09$ & $0.55 \pm 0.06$ & $0.50 \pm 0.10$ & $0.38 \pm 0.06$ & 0.233 \\
\hline
\end{tabular}

TAS: Toplam antioksidan durum, TOS: Toplam oksidatif durum, OSi: oksidatif stres indeksi, AOPP: Gelişmiş oksidasyon protein ürünleri, THiOL: Toplam thiol grupları, SE: Standart hata, a. b.c: aynı satırdaki farklı harflerle gösterilen ortalamalar arasındaki farklar önemlidir. $(\mathrm{P}<0.05)$

Ghasemi ve ark. (2014), broyler civcivlerinin performans ve bağırsak özellikleri üzerine etkisini değerlendirdiği çalışmada rasyona $\% 0,1 \% 0.2$ ve \% 0.3 sumak ekstraktı ilavesinin yem tüketimini kontrol grubuna kıyasla anlamlı derecede arttırdığını ( $P$ <0.05) ve en yüksek canlı ağırlık artışının \%0.2 sumak ekstraktı ilave edilen grupta elde edildiğini bildirmişlerdir. Valiollahi ve ark. (2014), sumak ve karabiber ilavesinin broyler civcivlerinin performansı üzerindeki etkisi isimli çalışmada, rasyonlarına sumak ve karabiber ilave edilen gruplarda yem tüketimi, canlı ağırlık artışı ve toplam canlı ağırlığının kontrol grubundan daha yüksek olduğunu bildirmişlerdir. Kheiri ve ark. (2015), broyler rasyonuna sumak ve kurutulmuş peynir altı suyu tozunun büyüme performansı, karkas özellikleri, bağırsak morfolojisi, mikrobiyal popülasyon, bazı biyokimyasal parametreleri ve Newcastle hastalığına karşı antikor titresi üzerindeki etkilerini araştırdıkları çalışmada, sumak ve peyniraltı suyunun birlikte ilave edilmesinin broyler civcivlerin yem tüketimi, canlı ağırlık artışını kontrol grubuna kıyasla arttırdığını belirtmişlerdir $(P<0.05)$. Mansoob (2011), broyler rasyonunda farklı seviyelerde sumak kullanımının yem tüketimi canlı ağırlık artışı ve yemden yararlanma oranında önemli etkiye sahip olduğunu göstermiştir $(P<0.05)$. Canlı ağırlık artışının ve yemden yararlanma oranının iyileşmesinin sumakta bulunan aktif maddeden (sinnamaldehit ve ögenol) kaynaklandığını belirtilmiştir (Mansoob, 2011). Yapılan çalışmalara göre besi performansıyla ilgili sonuçların mevcut çalışmamızla uyuşmamasının muhtemel sebebi yüksek yaz sıcaklıklarına denk gelmiş olması olabilir. Yüksek sıcaklığa bağlı olarak yem tüketimi ve yemden yararlanma azalmakta, gelişme gerilemekte ve ölüm oranı artmaktadır (Lott, 1991; May ve Cott, 1992).

Çalışmada sumak ilavesinin kesim özellikleri ve iç organ ağırıkları üzerine etkisi incelendiğinde sırt ve but ağırlıkları dışında incelenen kesim ve karkas ağırlıkları açısından gruplar arasında fark bulunmamıştır $(P>0.05)$. Buna karşın Zavaragh (2011) sarımsak ve sumak tozunun Japon bıldırcınlarının performans ve serum kompozisyonu üzerindeki etkilerini araştırmışlardır. En yüksek karkas ve karaciğer yüzdesini sırasıyla \%2 sarımsak ve sumak tozu ile \%2 sumak tozu içeren grupta bulmuşlardır $(\mathrm{P}<0.05)$.

Japon bıldırcınlarında sumağın göğüs et kalitesi özelliklerinden olan $\mathrm{pH}$ ve bıldırcınların göğüs eti renk özellikleri ( $L^{*}, a^{*}$ ve $b^{*}$ ) üzerinde etkisi önemli bulunmamıştır $(P>0.05)$. Bunun sebebini hava sıcaklığının et kalitesi üzerindeki etkisinden 
kaynaklandığına bağlayabiliriz (Altan ve ark., 2001). Ayrıca kesim öncesi stresininde et kalitesi üzerinde etkisi olmaktadır (Babj ve ark., 1982).

Japon bıldırcınlarında sumak ilavesinin oksidatif stres ve antioksidan kapasitesi değerlerini önemli düzeyde etkilediği tespit edilmiştir $(P<0.05)$ (Tablo 6). Sumak düzeyinin artışına bağlı olarak TAS değeri kontrol grubuna göre yükseltmiştir $(P=000)$. $\mathrm{Bu}$ bulguyla uyumlu olarak en yüksek Osi değeri kontrol grubunda en düşük ise $\% 3$ sumak grubunda tespit edilmiştir $(P=000)$. Alishah ve ark. (2012), yaptıkları çalışmalarında broyler yemlerine $\% 0$, $\% 0.25, \% 0.50$ ve $\% 1$ seviyelerinde sumak ilavesinin performans ve kan antioksidan düzeyi üzerine etkisini incelemişler ve sumak ilavesinin kandaki toplam antioksidan kapasitesi (TAC), malondialdehit (MDA) içeriği ve süperoksit dismutaz (SOD) ve glutatyon peroksidaz (GPX) enzim aktivitelerini etkilemediğini bildirmişlerdir $(P>0,05)$. Ayrıca diyete sumak ilavesinin ısı stresindeki başlangıç döneminde broyler tavuklarının performansını artırabilmesine rağmen, büyüme döneminde kan antioksidan değerlerini ve performansı etkilemediği sonucuna varmışlardır.

Çalışma sonucuna göre bıldırcın rasyonlarına sumak ilavesinin herhangi bir olumsuz etkisinin olmadığı, sıcak yaz şartlarında TAS ve OSi değerleri üzerine olumlu etkisinden dolayı yem katkı maddesi olarak kullanılabileceği belirlenmiştir.

\section{Kaynaklar}

Alishah AS, Daneshyar M, Aghazadeh A, 2013: The effect of dietary sumac fruit powder (Rhus coriaria $L$ ) on performance and blood antioxidant status of broiler chickens under continuous heat stress condition. Ital J Anim Sci., 12 (6), 39-43.

Altan A, Bayraktar H, Önenç A, 2001: Etlik Piliçlerde Sıcak Stresinin Et Rengi ve $\mathrm{pH}^{\prime}$ ı Üzerine Etkileri. Hayvansal Üretim Derg, 42 (2), 1-8.

Babj AS, Froning GW Nkoga DA, 1982. The effects of preslaughter environmental temperature in the presence of electrolyte treatment on turkey meat quality. Poult Sc, 61 (12), 2385-2389.

Başkol M, Dolbun Seckin K, Başkol G, 2014: Advanced oxidation protein products, total thiol levels and total oxidant/antioxidant status in patients with nash. Turk J Gastroenterol, 25 (1),32-37.

Çimrin T, Tunca Ri, 2012: Bıldırcın beslemede alternatif yem ve katkıların kullanımı. Iğdır Üni Fen Bilimleri Enst Derg, 2 (3), 109-116.

Genchev A, Mihaylov R, 2008: Slaughter analysis protocol in experiments using Japanese quails (Coturnix Japonica). Trakia J. Sci, 6, 66-71.
Ghasemi R, Faghani M, Reza JP, Khonmirzaie N, Rahimian $Y, 2014$ : Using Sumac (Rhus coriaria L.) extract affect performance and intestinal characteristics of broiler chicks. Scholarly J. Agric. Sci., 4 (8), 442-445.

Golzadeh MP, Farhoomand and Daneshyar M. 2012: Dietary Rhus coriaria L. Powder Reduces the Blood Cholesterol, VLDL-c and Glucose, but Increases Abdominal Fat in Broilers. S. Afr. J. Anim. Sci., 42 (4), 399-405.

Gümüş H, Oguz NM, Bugdayci KE, Oğuz FK, 2018: Effects of sumac and turmeric as feed additives on performance egg quality traits and blood parameters of laying hens. R. Bras. Zootec., 47, 1-7.

Kutlu HR, Şahin A, 2017: Kanatlı Beslemede Güncel Çalışmalar ve Gelecek için Öneriler. Hayvansal Üretim Derg, 58 (2),66-79.

Kheiri F, Rahimian Y, Nasır J, 2015: Application of sumac and dried whey in female broiler feedArch. Anim Breed, 58, 205-210.

Lott BD, 1991: The effect of feed intake on body temperature and water consumption of male

broilers during heat exposure. Poult Sci, 70, 410-417.

Mansoob HN, 2012: Effect of different levels of Sumac Powder (Rhus Coriaria L.) on performance, carcass and blood parameters of broiler Chickens. Annals of Biol. Res, 2 (5), 647-652.

May JD, Cott BD, 1992: Feed consumption patterns of broilers at high environmental temperatures. Poult Sci, 71, 331-336.

NRC, U. 1994: Science and judgment in risk assessment. Washington: National Academy of Sciences, Whashington, USA.

Salih YG, Gürbüz Y, 2015: Sumac (Rhus coriaria L.) and Ginger (Zingiber officinale) as Feed additive in Poultry Nutrition., KSU J Nat Sci, 18 (3), 44-48.

SPSS I. 1999: SPSS for Windows. Chicago, Illinois.

Shidfar F, Rahideh ST, Rajab A, 2014: The Effect of Sumac (Rhus coriaria L.) Powder on Serum Glycemic Status. ApoB. ApoA-I and Total Antioxidant Capacity in Type 2 Diabetic Patients. Iran. J. Pharm. Res., 13 (4), 1249-1255.

Valiollahi MR, Rahimian Y, Miri Y, Asgarian F, Rafiee A, 2014: Effect of ginger (Zingiber officinale) and black pepper (Piper nigrum L.) powder on performance, haematological parameters and antibody titre in broiler chicks. Res. Opinions Anim. Vet. Sci., 4 (3), 128-132.

Zavaragh FM, 2011: Influence of Garlic and Sumac Powder (Rhus coriaria L.) on Performance, Carcass and Blood Biochemical of Japanese Quails Scholars Research Library. Annals of Biological Research, 2 (6), 542-545.

${ }^{*}$ Yazışma Adresi: Nurcan KIRAR

Harran Üniversitesi Sağlık Bilimler Enstitüsü, Şanlıurfa, Türkiye.

e-mail: a155116019@hotmail.com 